\title{
Correlation of oesophageal acid exposure with Barrett's oesophagus length
}

\author{
R Fass, R W Hell, H S Garewal, P Martinez, G Pulliam, C Wendel, R E Sampliner
}

\begin{abstract}
Background-Gastro-oesophageal reflux disease (GORD) plays a major role in the development of Barrett's oesophagus. However, it has yet to be elucidated what factors determine the length of Barrett's mucosa in each individual patient.

Aims-To determine if there is a correlation between oesophageal acid exposure and the length of Barrett's mucosa. We also compared the extent of oesophageal acid exposure between patients with short segment (SSBE) and long segment (LSBE) Barrett's oesophagus.

Methods-Twenty seven patients with Barrett's oesophagus were recruited prospectively into the study from the outpatient gastroenterology clinic at the Southern Arizona VA Health Care System. Diagnosis of Barrett's oesophagus and its anatomical characteristics were determined during upper endoscopy. Ambulatory 24 hour oesophageal pH monitoring assessed the extent of oesophageal acid exposure.
\end{abstract}

Results-There was a significant correlation between per cent total time pH less than 4 and length of Barrett's mucosa $(r=0.6234, p=0.0005)$. In addition, there was a significant correlation between per cent upright and supine time $\mathrm{pH}$ less than 4 and length of Barrett's mucosa $(r=0.5847, \quad \mathrm{p}=0.0014$ and $r=0.6265$ p=0.0006, respectively). Patients with SSBE had significantly less oesophageal acid exposure than patients with LSBE, in terms of both per cent total time and per cent supine time pH less than $4(p<0.05)$.

Conclusions-The length of Barrett's mucosa correlated with the duration of oesophageal acid exposure. Patients with LSBE experienced significantly more oesophageal acid exposure than patients with SSBE. Duration of oesophageal acid exposure appears to be an important contributing factor in determining the length of Barrett's mucosa.

(Gut 2001;48:310-313)

Keywords: Barrett's oesophagus; intestinal metaplasia; oesophageal $\mathrm{pH}$ monitoring; oesophageal acid exposure

The diagnosis of Barrett's oesophagus hinges on the presence of intestinal metaplasia that replaces the normal stratified squamous epithelium of the oesophagus. ${ }^{1}$ Barrett's oesophagus has attracted much attention because of its potential for the development of adenocarcinoma of the oesophagus. Currently, this tumour is the fastest rising cancer in the USA. $^{2}{ }^{3}$

Reflux of gastric content into the oesophagus has been suggested to be responsible for the development of Barrett's epithelium. In patients presenting with gastro-oesophageal reflux symptoms, $12 \%$ were found to have Barrett's oesophagus. ${ }^{4}$ The prevalence is markedly higher in patients with erosive oesophagitis $(36 \%) .{ }^{4}$ Furthermore, patients with Barrett's oesophagus tend to have relatively higher oesophageal acid exposure compared with normal subjects, patients with non-erosive reflux disease, or those with erosive oesophagitis. ${ }^{5}$ Fitzgerald et al have recently shown that short pulses of acid exposure increased cell proliferation of Barrett's epithelium ex vivo while continuous acid exposure induced differentiation and reduced proliferation. ${ }^{6}$ This study also demonstrated that the effects of acid exposure are $\mathrm{pH}$ dependent as well as time dependent.

Use of antireflux medications in patients with gastro-oesophageal reflux disease (GORD) leads to improvement or complete symptom resolution and healing of mucosal inflammation. A similar approach has been used in patients with Barrett's oesophagus. However, thus far normalisation of oesophageal acid exposure, even with high doses of proton pump inhibitors, has not resulted in significant regression of Barrett's mucosa. ${ }^{7-9}$

The exact pathophysiology that leads to the development of Barrett's epithelium remains to be fully elucidated. It is clear that most patients with GORD do not develop Barrett's oesophagus. Those that do develop Barrett's mucosa appear to do so within a relatively short period of time. ${ }^{10}$ Age of onset, duration of symptoms, and complications of GORD have been demonstrated to be markers of increased risk of Barrett's oesophagus. ${ }^{11}$ It is still unknown, however, what factors specifically determine the length of Barrett's mucosa. Further exploration of the causes that lead to longer Barrett's mucosa is necessary. Thus far, it appears that the longer the Barrett's mucosa the higher the risk for the development of dysplasia. ${ }^{12}$

The aim of this study was to determine if there is a correlation between oesophageal acid exposure and length of Barrett's mucosa. We hypothesised that increase in oesophageal exposure to gastric acid is an important contributing factor in determining the length of Barrett's oesophagus.

Abbreviations used in this paper: GORD, gastro-oesophageal reflux disease; SSBE, short segment Barrett's oesophagus; LSBE, long segment Barrett's oesophagus. 


\section{Materials and methods}

PATIENTS

A total of 27 patients with endoscopically proved Barrett's oesophagus were enrolled in a prospective fashion into the study. All patients were recruited from the general gastroenterology outpatient and specialised Barrett's oesophagus clinics at the Southern Arizona VA Health Care System.

After obtaining informed consent, patients underwent upper endoscopy to determine the presence of Barrett's oesophagus. If the finding of Barrett's epithelium was confirmed by histology, patients underwent ambulatory 24 hour oesophageal $\mathrm{pH}$ monitoring. The antireflux regimen was discontinued 10 days prior to $\mathrm{pH}$ testing in those subjects who were receiving ongoing therapy.

Patients were excluded if they were unable to discontinue antireflux treatment, declined or were unable to complete 24 hour oesophageal $\mathrm{pH}$ monitoring, had dysplasia or oesophageal cancer in Barrett's epithelium, or were unwilling or unable to provide informed consent.

This study was approved by the human subjects committee of the University of Arizona.

UPPER ENDOSCOPY

After an overnight fast, patients were placed in the left lateral decubitus position. Sedation was achieved using midazolam (Roche, Nutley, New Jersey) with or without Demerol (Sanofi Winthrop, New York, New York, USA). Thereafter, the endoscope was inserted via the mouth into the oesophagus. The stomach and duodenum were also inspected to exclude possible lesions. The distal portion of the oesophagus was carefully evaluated to determine the presence of red colour and velvet-like texture extending into the oesophagus and/or mucosal injury. If Barrett's oesophagus was suspected, biopsies were obtained every $2 \mathrm{~cm}$. If intestinal metaplasia was present in one biopsy, then almost all others were also positive, regardless of the length of Barrett's oesophagus. Barrett's oesophagus was defined as the presence of intestinal metaplasia on biopsy. Measurement of Barrett's length was performed from the proximal margin of continuous Barrett's epithelium to the end of the tubular oesophagus or the proximal margin of hiatal hernia folds. ${ }^{13}$ Long segment Barrett's oesophagus (LSBE) and short segment Barrett's oesophagus (SSBE) were defined as intestinal metaplasia in the distal oesophagus $\geqslant 3 \mathrm{~cm}$ and $<3 \mathrm{~cm}$ in length, respectively. ${ }^{12}$ Hiatal hernia was considered present if the oesophagogastric junction was displaced more than $2 \mathrm{~cm}$ proximal to the diaphragmatic hiatus.

\section{AMBULATORY 24 HOUR OESOPHAGEAL pH} MONITORING

After an overnight fast, a $\mathrm{pH}$ probe with lower oesophageal sphincter identifier (Synectics Medical, Digitrapper MK III, Stockholm, Sweden) was inserted via the nose into the stomach. The lower oesophageal sphincter identification manometry assembly is a simple system for water perfused manometry using the combined $\mathrm{pH}$ and water perfused pressure catheter. This system has been shown to provide accurate placement of the $\mathrm{pH}$ probe in the oesophagus, which was comparable with standard oesophageal manometry followed by $\mathrm{pH}$ probe placement. ${ }^{14}$ The pressure lumen is located $5 \mathrm{~cm}$ above the distal $\mathrm{pH}$ sensor. By using the station pull through technique $(0.5$ $\mathrm{cm}$ increments), identification of the proximal margin of the lower oesophageal sphincter was achieved. The $\mathrm{pH}$ probe was then placed $5 \mathrm{~cm}$ above the upper margin of the lower oesophageal sphincter and was connected to a digital portable recorder. A reference electrode was attached to the upper chest. Patients were instructed to keep a diary recording meal times, position changes, and time and type of symptoms. Patients were encouraged to pursue their everyday activities and usual diet. At the beginning and end of the study, the electrode and system were calibrated in standard solutions of $\mathrm{pH} 1$ and 7. Reflux was defined as $\mathrm{pH}$ less than 4 and reflux time as the interval until $\mathrm{pH}$ is greater than 4. The presence of GORD was established when the per cent total time oesophageal $\mathrm{pH}$ less than 4 was greater than $4.2 \% .^{15}$ Analysis of the recorded data was performed using standard commercially available computer software (Synectics, Stockholm, Sweden).

\section{STATISTICAL ANALYSIS}

Results are presented as mean (SEM). An independent two sample $t$ test was used to test for a difference between the LSBE and SSBE groups for age and the three variables. The association between Barrett's length and ambulatory 24 hour oesophageal $\mathrm{pH}$ monitoring (total, upright, and supine) as well as hiatal hernia length was evaluated with the Pearson product moment correlation and unadjusted significance levels ( $\mathrm{p}$ values).

\section{Results}

All 27 patients who completed the study were males. Mean age was 65.3 (2.2) years (range 38-83). Mean Barrett's length was 4.0 (0.6) $\mathrm{cm}$ (range 1-14). Mean per cent total time $\mathrm{pH}$ less than 4 was 19.4 (3.5) (range 3-75); in the

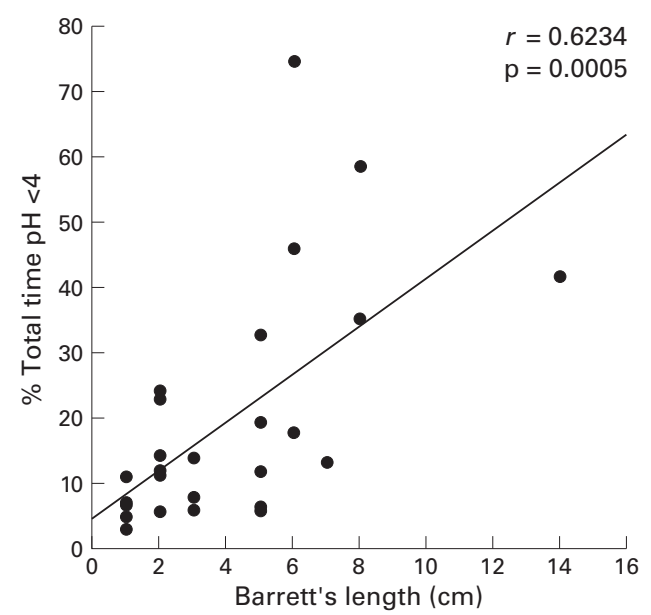

Figure 1 Correlation between length of Barrett's mucosa and per cent total time $\mathrm{pH}<4$. 


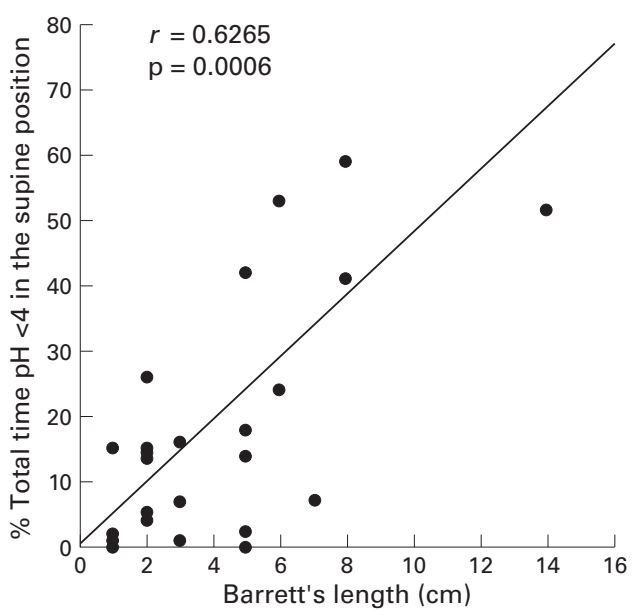

Figure 2 Correlation between length of Barrett's mucosa and per cent supine time $\mathrm{pH}<4$.

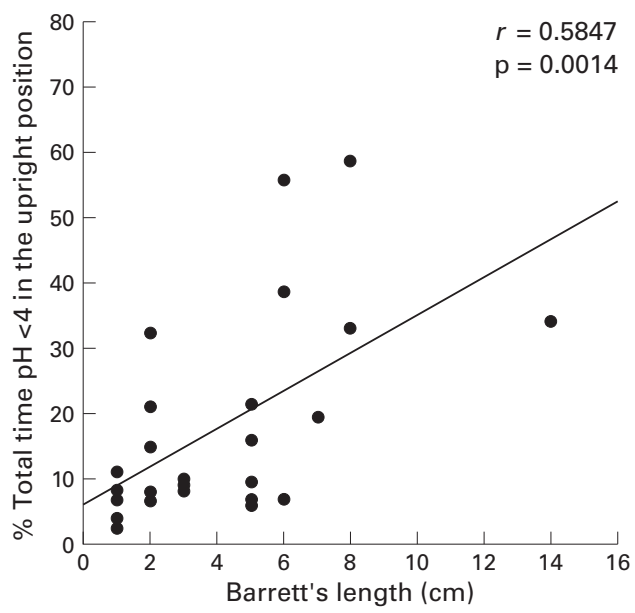

Figure 3 Correlation between length of Barrett's mucosa and per cent upright time $\mathrm{pH}<4$.

supine position, 19.7 (4.6) (range 0-92); and in the upright position, 17.6 (2.9) (range 2.5-59). Only one patient had a normal $\mathrm{pH}$ testing $(3.0 \%)$.

There was a significant correlation between per cent total time $\mathrm{pH}$ less than 4 and the length of Barrett's mucosa $(r=0.62, \mathrm{p}=0.0005)$ (fig 1). Furthermore, there was a significant correlation between per cent supine and upright time $\mathrm{pH}$ less than 4 and length of Barrett's mucosa $(r=0.63, \mathrm{p}=0.0006$ and $r=0.5847, \mathrm{p}=0.0014$, respectively) (figs 2,3 ).

Twelve of the patients had SSBE and 15 had LSBE. Table 1 summarises the characteristics

Table 1 Patient characteristics

\begin{tabular}{lll}
\hline & SSBE $(n=12)$ & LSBE $(n=15)$ \\
\hline Age (y) & $67.4(3.4)$ & $64.5(2.8)$ \\
Range & $38-83$ & $48-81$ \\
Sex & All male & All male \\
Mean Barrett's length (cm) & $1.5(0.2)$ & $5.9(0.7)$ \\
$\quad$ Range (cm) & $1-2$ & $3-14$ \\
Mean hiatal hernia length (cm) & $1.5(0.4)$ & $3.4(0.5)^{\star}$ \\
$\quad$ Range (cm) & $0-4$ & $1-7$ \\
pH testing & $10.8(2.0)$ & $26.3(5.5)^{\star}$ \\
Mean total time (\%) & $11.8(2.4)$ & $22.3(4.6)$ \\
Mean upright (\%) & $7.6(2.6)$ & $28.5(6.9)^{\star}$ \\
Mean supine (\%) &
\end{tabular}

SSBE, short segment Barrett's oesophagus (Barrett's length $<3 \mathrm{~cm}$ ); LSBE, long segment Barrett's oesophagus (Barrett's length $>3 \mathrm{~cm}$ ). ${ }^{\star} \mathrm{p}<0.05$. of the two groups. There was no significant difference between the ages of the two groups $(p=0.5)$. There was a significant difference in per cent total time $\mathrm{pH}$ less than 4 between patients with LSBE $(26.3(5.5))$ and those with $\operatorname{SSBE}(10.8(2.0))(\mathrm{p}=0.02)$. There was also a significant difference in per cent supine time $\mathrm{pH}$ less than 4 between LSBE $(28.5$ (6.9)) and $\operatorname{SSBE}(7.6(2.6))$ patients $(\mathrm{p}=0.02)$. There was a numerical difference in the per cent upright time $\mathrm{pH}$ less than 4 between patients with LSBE (22.3 (4.6)) and those with SSBE (11.8 (2.4)), which tended towards statistical significance $(\mathrm{p}=0.07)$.

Hiatal hernia was documented in all patients with LSBE and in nine $(75 \%)$ patients with SSBE. There was a significant difference between mean length of hiatal hernia of patients with LSBE $(3.4(0.5) \mathrm{cm})$ and those with $\operatorname{SSBE}(1.5(0.4) \mathrm{cm})(\mathrm{p}=0.008)$.

\section{Discussion}

This study has demonstrated the close correlation between Barrett's length and extent of oesophageal acid exposure. The longer the Barrett's mucosa, the higher the per cent total time, upright time, and supine time $\mathrm{pH}$ less than 4. In two other retrospective studies a similar correlation with per cent total time $\mathrm{pH}$ less than 4 was documented and the authors concluded that the length of Barrett's oesophagus was significantly and directly related to the degree to which the oesophageal mucosa was exposed to the refluxed gastric acid. ${ }^{16}{ }^{17}$ In addition, Öberg et al have demonstrated that the extent of Barrett's oesophagus is inversely correlated with lower oesophageal sphincter pressure and length. ${ }^{17}$ However, both of these studies did not specify any correlation with per cent upright and supine time $\mathrm{pH}$ less than 4 .

When our study group was divided into patients with SSBE and those with LSBE, there was a marked difference in acid exposure parameters, as determined by 24 hour oesophageal $\mathrm{pH}$ monitoring. These results are supported by Loughney et al who compared patients with SSBE with those with LSBE. ${ }^{18}$ However, in their study the $\mathrm{pH}$ probe was placed at 0 and $5 \mathrm{~cm}$ above the proximal margin of the lower oesophageal sphincter. There was significantly higher acid exposure in the LSBE group at both locations, suggesting that not only the extent but also the height of acid exposure may determine the length of Barrett's mucosa.

The duration of oesophageal acid exposure may not be the only factor that contributes to the length of Barrett's mucosa. Duodenogastrooesophageal reflux may also play an important role in determining not only the development but also the maximum length of Barrett's oesophagus. Bile acids, lysoeysolecithin, and pancreatic enzymes (trypsin) appeared to be injurious to the oesophageal mucosa. ${ }^{19} \mathrm{Al}$ though correlation between the extent of duodenogastro-oesophageal reflux and the length of Barrett's mucosa was not carried out, several studies have shown that patients with Barrett's oesophagus had the highest exposure compared with different GORD groups and 
control subjects. ${ }^{20} 21 \mathrm{~A}$ combination of both increased acid exposure and dudenogastrooesophageal reflux appears to be the most common pattern in patients with Barrett's oesophagus. ${ }^{22}$

Development of Barrett's oesophagus appears to be a process that occurs within a very short period of time in which Barrett's epithelium reaches its maximum length. ${ }^{10}$ There is little progression or regression after that, regardless of whether or not oesophagitis is present. ${ }^{10}$ In general, attempts to normalise oesophageal acid exposure by aggressive antireflux treatment have failed to produce significant changes in the length of Barrett's oesophagus. ${ }^{93}$ Ouatu-Lascar et al have suggested that effective intra-oesophageal acid suppression may be beneficial in the long term treatment of Barrett's oesophagus, promoting more differentiated Barrett's oesophagus epithelium while minimising cell proliferation. ${ }^{7}$ The importance of aggressive acid suppression in patients with Barrett's oesophagus is also supported by our study results. However, attention should be paid to the length of Barrett's mucosa prior to initiating medical therapy. Patients with longer segments may require higher doses of antireflux therapy than patients with shorter segments of Barrett's oesophagus.

In recent years a debate has emerged about the clinical significance of SSBE. SSBE is more common in the general population than LSBE but does not appear to harbour the same risks for adenocarcinoma of the oesophagus. ${ }^{24}$ Both SSBE and LSBE are considered to be sequela of GORD and may represent a continuum of the same lesion rather than two separate entities. The correlation between the length of Barrett's oesophagus and the extent of acid exposure that we demonstrated in this study supports the former hypothesis.

Our study has also demonstrated that there is a close correlation between Barrett's length and both per cent upright and supine time $\mathrm{pH}$ $<4$. This may indicate that the combination of both nocturnal and diurnal oesophageal acid exposure is important in determining the length of Barrett's mucosa. This finding is supported by DeMeester et al who demonstrated that combined acid reflux pattern is associated with more severe GORD than nocturnal or diurnal oesophageal acid exposure alone. ${ }^{25}$ However, our study is the first to show a correlation between both patterns of acid reflux and the length of Barrett's oesophagus.

In summary, a direct correlation between the extent of oesophageal acid exposure and the length of Barrett's mucosa has been demonstrated. This correlation was further maintained in either the supine or erect position. Although the extent of acid reflux may not be the only factor that determines the length of Barrett's mucosa, thus far there are no other factors that have been shown to have such a close relationship. Future studies seeking other possible causes that determine Barrett's length may provide us with a better insight into how Barrett's mucosa can be reversed and even potentially prevented.

Presented in part at the annual meeting of the American Gastroenterological Association, Orlando, Florida, USA, May 1999.

1 Spechler SJ, Goyal RK. Barrett's esophagus. N Engl f Med 1986;315:362-71

2 Blot W, Devesa S, Kneller R, et al. Rising incidence of adenocarcinoma of the esophagus and gastric cardia. $7 A M A$ 1991;265:1287-9.

3 Devesa SS, Blot WJ, Fraumeni JF. Changing patterns in the incidence of esophageal and gastric carcinoma in the United States. Cancer 1998;83:2049-53.

4 Winters C, Spurling TJ, Chobanian SJ, et al. Barrett's sophagus: a prevalent, occult complication of gastroesophageal reflux disease. Gastroenterology 1987;92:118-24.

5 Chow WH, Finkle WD, McLaughlin JK, et al. The relationship of gastroesophageal reflux disease and its treatment to adenocarcinoma of the esophagus and gastric cardia. fAMA 1995;274:474-7.

6 Fitzgerald RC, Omary MB, Triadafilopoulos G. Dynamic effects of acid on Barrett's esophagus: an ex vivo proliferation and differentiation model. $\mathcal{F}$ Clin Invest 1996;98:2120-8.

7 Ouatu-Lascar R, Fitzgerald RC, Triadafilopoulos G. and the effects of acid suppression. Gastroenterology 1999; 117:327-35.

8 Sampliner RE. Effect of up to 3 years of high dose lansoprazole on Barrett's esophagus. Am f Gastroenterol 1994;89: zole on $1844-8$.

9 Clark GWB, DeMeester TR. Surgical management of Barrett's esophagus. Ann Chir Gynaecol 1995;84:139-44.

10 Cameron AJ, Lomboy CT. Barrett's esophagus: age, prevalence and extent of columnar epithelium. Gastroenter ology 1992;103:1241-5.

11 Eisen GM, Sandler RS, Murray S, et al. The relationship between gastroesophageal reflux disease and its complications with Barrett's esophagus. Am f Gastroenterol 1997;92: $27-31$.

12 Sampliner RE. The Practice Parameters Committee of the ACG. Practice guidelines on the diagnosis, surveillance, and therapy of Barrett's esophagus. Am f Gastroenterol 1998;93:1028-32.

13 Sampliner RE, Fennerty MB, Garewal HS. Reversal of Barrett's esophagus with acid suppression and multipolar electrocoagulation: preliminary results. Gastrointest Endosc 1996;44:523-5.

14 Klingler PJ, Hinder RA, Wetscher GJ, et al. Accurate placement of the esophageal $\mathrm{pH}$ electrode for 24-hour $\mathrm{pH}$ monitoring using a combined $\mathrm{pH} /$ manometry probe. $\mathrm{Am} \mathcal{F}$ Gantroenterol 2000;95:906-9.

15 Weiner GJ, Morgan TM. Ambulatory 24-hour esophageal $\mathrm{pH}$ monitoring, reproducibility and variability of $\mathrm{pH}$ parameters. Dig Dis Sci 1988;33:1127-33.

16 Sontag SJ, Schnell T, Chejfec G, et al. Length of Barrett's epithelium corresponds directly to esophageal acid contact time in patients with reflux. Gastroenterology 1996;110: A262.

17 Öberg S, DeMeester TR, Peters JH, et al. The extent of Barrett's esophagus depends on the status of the lower esophageal sphincter and the degree of esophageal acid exposure. f Thorac Cardiovasc Surg 1999;117:572-80.

18 Loughney T, Maydonovitch CL, Wong RKH. Esophageal manometry and ambulatory 24-hour $\mathrm{pH}$ monitoring in matients with short and long segment Barrett's esophagus. patients with short and long segment

19 Kivilaakso E, Promm D, Silen W. Effect of bile salts and related compounds on isolated esophageal mucosa. Surgery 1980;87:280-5

20 Champion G, Richter JE, Vaezi JF, et al. Duodenogastroesophageal reflux: relationship to $\mathrm{pH}$ and importance in Barrett's esophagus. Gastroenterology 1994;107:747-54.

21 Vaezi MF, Richter JE. Complicated Barrett's esophagus: role of acid and bile. Am F Gastroenterol 1994;89:1630.

22 Vaezi MF, Richter JE. Role of acid and duodenogastroesophageal reflux in gastroesophageal reflux disease. Gastroenterology 1996;111:1192-9.

23 Cooper BT, Neumann CS, Cox MA, et al. Continuous treatment with omeprazole $20 \mathrm{mg}$ daily for up to 6 years in

24 Hirota WK, Loughney TM, Lazas DJ, et al. Specialized intestinal metaplasia, dysplasia, and cancer of esophagus and esophagogastric junction: prevalence and clinical data. Gastroenterology 1999;116:277-85.

25 DeMeester TR, Johnson LF, Joseph GJ, et al. Patterns of gastroesophageal reflux in health and disease. Ann Surg 1976;184:459-64. 